\section{RESPONDING TO GENDER-BASED VIOLENCE IN DISASTERS}

\section{To the Editor:}

In the editorial Responding to Gender-based Violence in Disasters: Grappling With Research Methods to Clear the Way for Planning, Rosborough et al discuss challenges to measuring and reporting on gender-based violence (GBV) in disasteraffected populations. ${ }^{1}$ The authors also comment on our research contribution, which documented an increase in GBV among female internally displaced people following Hurricane Katrina well into a protracted phase of displacement. ${ }^{2}$ We greatly appreciate the editorialists' commentary and summary of the salient barriers to adequately assessing the prevalence of GBV in the context of disasters. Here, we seek to clarify our methods and choice of baseline GBV prevalence estimates. ${ }^{3}$

We assessed the change in the rate of GBV among internally displaced people in Mississippi by comparing rates between 2 phases of sampling, 1 conducted in 2006 and 1 in 2007.2,4 The editorialists suggested that aggregate GBV statistics for stable populations-such as the 1996 National Violence Against Women Survey, the 2006 Behavioral Risk Factor Surveillance System (BRFSS) intimate partner violence (IPV) survey, or state crime statistics-were potential sources of "proxy statistics" to power our analyses. ${ }^{5,6}$ The $1996 \mathrm{Na}$ tional Violence Against Women Survey was more than 10 years old at the time of our study, and the 2006 BRFSS in Mississippi did not include the optional IPV module in the years immediately preceding the hurricane. ${ }^{5,7}$ Furthermore, national and state crime estimates are based on different modes of reporting, are typically relevant to 1 component of GBV for a specific catchment area, and are not based on definitions and measurement modalities such as those highlighted in the World Health Organization's Ethical and Safety Recommendations for Researching, Documenting, and Monitoring Sexual Violence in Emergencies. ${ }^{8,9}$ Despite the important limitations of using baseline GBV estimates from general populations, we did indeed contextualize our findings by discussing how several of our GBV estimates compared with the state of Mississippi and the nation at large. ${ }^{10}$

Our decision to use baseline GBV rates from our own study originated from the same concern that the editorialists cite as a major problem: aggregate statistics from stable settings are often "underestimates of the population under study" and the "higher prevalence of vulnerability" among disaster-affected people often precludes direct comparisons to the general population. Given the methodology differences that were used to obtain baseline estimates (including sampling frames, respondent characteristics, item measurement, and representativeness of the results) in our study compared with those suggested above, the use of these statistics to establish our population baseline GBV prevalence estimate would have been particularly problematic. We thus used baseline GBV statistics derived from identical GBV-item wording in our successive surveys, both of which were conducted in similar populations, to provide the best baseline estimates with minimal variability and by using a lifetime recall period with conservative criteria. Although this measurement of GBV was not perfect, it was consistent and an improvement to using estimates drawn from a nonrepresentative population.

We ardently agree with the need for consistent definitions of GBV when conducting GBV research, particularly in crosscultural conflict and disaster settings. Our survey items corresponded to internationally recognized standards for defining GBV. ${ }^{11,12}$ We made clear distinctions in identifying specific variants of GBV (IPV and sexual violence) and the time period in which they occurred to better define our composite GBV measure.

Finally, it is important to note that we did not use major depressive disorder as a "proxy" measure for GBV, nor did we use it as a substitute for baseline GBV prevalence data. Rather, we used mental health measures to cross-validate our measures of GBV. ${ }^{13}$ Our overall measure of GBV and IPV showed consistent relations across time periods with major depressive disorder, severity of major depressive disorder, and suicidal ideation. Key to these associations was the insignificant interaction term between time of survey and mental health symptoms, suggesting that the relation between mental health and GBV was consistent across time periods. Although this relation remained stable between time periods, the overall rate of GBV increased. If a thermometer is off by $10^{\circ}$, it may not provide an accurate temperature but it will still tell you when the temperature changes.

Scientists should continue to grapple with research methods when measuring GBV in the context of disasters. In our case, complex actions were required to make a humble assertion about a change in the rates of GBV into the protracted phase of displacement following Hurricane Katrina. In the face of extreme measurement challenges, scientists should not shy away from attempting to research this public health issue, one which can have more devastating effects on its victims than the disaster that it follows.

Michael Anastario, PhD, Nadine Shehab, PharmD, and Lynn Lawry, MD, MSPH, MSc

Uniformed Services University of the Health Sciences and Johns Hopkins University

DOI: 10.1097/DMP.0b013e3181b7e67c

\section{REFERENCES}

1. Rosborough S, Chan JL, Parmar P. Responding to gender-based violence in disasters: grappling with research methods to clear the way for planning. Disaster Med Public Health Preparedness. 2009;3:8-10.

2. Anastario M, Shehab N, Lawry L. Increased gender-based violence 
among women internally displaced in Mississippi 2 years post-Hurricane Katrina. Disaster Med Public Health Preparedness. 2009;3:18-26.

3. World Health Organization. WHO Multi-country Study on Women's Health and Domestic Violence Against Women. http://www.who.int/ gender/violence/who_multicountry_study/en/index.html. Accessed March 25, 2009

4. Larrance R, Anastario M, Lawry L. Health status among internally displaced persons in Louisiana and Mississippi travel trailer parks. Ann Emerg Med. 2007;49:590-601.

5. Tjaden P, Thoennes N. Prevalence, Incidence, and Consequences of Violence Against Women: Findings From the National Violence Against Women Survey. http://www.ncjrs.gov/txtfiles/172837.txt. Accessed March 25, 2009.

6. Centers for Disease Control and Prevention. 2006 Behavioral Risk Factor Surveillance System Questionnaire. http://www.cdc.gov/brfss/ questionnaires/pdf-ques/2006brfss.pdf. Accessed March 25, 2009.

7. Mississippi Department of Health. Behavioral Risk Factor Surveillance System Home. http://www.msdh.state.ms.us/brfss/index.htm. Accessed March 25, 2009.

8. Ward J. Violence Against Women: A Statistical Overview, Challenges and Gaps in Data Collection and Methodology and Approaches for Overcoming Them. UN Division for the Advancement of Women in collaboration with Economic Commission for Europe (ECE) and World Health Organization (WHO) Expert Group Meeting. http://www.un.org/ womenwatch/daw/egm/vaw-stat-2005/docs/expert-papers/Ward.pdf. Accessed March 25, 2009.

9. World Health Organization. WHO Ethical and Safety Recommendations for Researching, Documenting and Monitoring Sexual Violence in Emergencies. http://www.who.int/gender/documents/OMS_EthicsESSafety10 Aug07.pdf. Accessed March 25, 2009.

10. Crime in the United States 2004 Uniform Crime Reports. http://www. fbi.gov/filelink.html?file=/ucr/cius_04/documents/CIUS2004.pdf. Accessed March 25, 2009.

11. United Nations International Research and Training Institute for the Advancement of Women. What Is Gender Based Violence? http:// www.un-instraw.org/en/index.php? option $=$ contentËtask $=$ view $\mathcal{E} i d=909$ Eु Itemid=0. Accessed March 25, 2009.

12. Reproductive Health Response in Conflict Consortium. Gender-Based Violence Tools Manual: For Assessment, Program Design, Monitoring and Evaluation in Conflict-Affected Settings http://www.rhrc.org/ resources/gbv/gbv_tools/manual_toc.html. Accessed March 25, 2009.

13. Anastario MP, Larrance R, Lawry L. Using mental health indicators to identify postdisaster gender-based violence among women displaced by Hurricane Katrina. J Womens Health (Larchmt). 2008;17:1437-1444.

\section{DISASTER 101: A NOVEL APPROACH TO HEALTH CARE STUDENTS' DISASTER MEDICINE AND EMERGENCY PREPAREDNESS TRAINING}

\section{To the Editor:}

Calls to develop skill-based competencies for emergency preparedness for health professionals-including physician trainees-predate the terrorist attacks of September 11, 2001. In June 2001, an American College of Emergency Physicians task force recommended that residents and medical students achieve proficiency in bioterrorism and weapons of mass destruction. ${ }^{1}$ Unfortunately, in the years following the 9/11 terrorist attacks, emergency preparedness education assessment largely focused on practicing physicians and not trainees..$^{2-5}$

In 2003, the Association of American Medical Colleges and the Institute of Medicine published reports encouraging early introduction of bioterrorism topics in medical school. The Association of American Medical Colleges report Training
Future Physicians about Weapons of Mass Destruction was the first to detail a vertical integration of bioterrorism curricula into all 4 years of medical education. ${ }^{6}$ In response to these reports, medical schools increased the attention paid to bioterrorism topics. In 2004, of 125 US medical schools, 104 reported that "biological/chemical terrorism" was included in $\geq 1$ required medical school courses. ${ }^{7}$

Yet US medical schools have been slow to develop standalone curricula that capture the academic breadth of disaster medicine. For example, a search of the Association of American Medical Colleges Course Details database using the terms "disaster," or "preparedness," or "casualty," or "bioterrorism," or "triage," revealed only 2 courses with any of the above terms in their title. ${ }^{8}$ With the exception of the notable work from some of our public health educators-for example, those at Columbia University-few medical schools have implemented core competencies for all health professionals in emergency preparedness such as those recently advocated by the American Medical Association's Expert Working Group. ${ }^{9}$

Thus, disaster medicine and emergency preparedness remain peripheral components of traditional medical education in the United States. Research on this topic is also lacking. We found only 2 published articles that specifically address the feasibility and efficacy of implementing disaster training to medical students. ${ }^{10,11}$

To address this research and training gap, we developed a 3-hour educational demonstration project to determine whether there was a novel method to teach medical students key concepts of disaster medicine. Using a pre-/posttest design, we measured the extent to which fourth-year medical students perceive, rapidly learn, and apply basic concepts of disaster medicine and emergency preparedness.

We sought to introduce concepts of disaster medicine immediately without the necessity of seeking university approval for a new course or changing an existing course. An application was submitted to the Office of Medical Education to offer our course, "Disaster 101," as an elective for fourth-year medical students.

An expert curriculum panel was convened consisting of 4 emergency medicine faculty physicians along with paramedic, emergency management, law enforcement, education, and training experts from the South Carolina Allied Health Education Consortium. The primary goal of the expert panel was to condense dozens of hours of existing lecture material into just 3. Via a modified Delphi technique, the panel pared down hundreds of competencies and competency domains into just 8 . In addition to a 90-minute didactic, 2 performance-based training exercises were developed. These included a hazardous material scene where students dressed and decontaminated a patient exposed to a toxin and a surprise mass casualty incident scenario with 100 life-sized mannequins.

Nearly all of the students who completed the 3-hour course accomplished their mass casualty incident performance ob- 